\title{
EL ARRENDAMIENTO DE BIENES DE MENORES E INCAPACES
}

\author{
Alex Plácido Vilcachagua
}

\section{INTRODUCCION}

En cl aspecto patrimonial, el régimen jurídico de la patria potestad, tutcla y la curatela confiere a los padres, tutores y curadores, respectivamente, la facultad de arrendar los bienes de los menores e incapaces; restringiendo, en algunos casos, tal atribución al cumplimiento previo de determinados requisitos. Sin embargo, al interior de la organización jurídica-positiva de la Institución Protectora de menorese incapaces se advierte la existencia de antagonismos que, en la práctica, podrían generar perjuicios a los interesados.

En cste breve trabajo, pretendemos determinar los defectos y deficiencias existentes en el régimen jurídico de la patria potestad, la tutela y la curatela relativas a la facultad de arrendar bienes de menores c incapaces proponiendo, según cl caso, las enmicndas necesarias para reducir o climinar los daños que podrian sufrir los mismos.

\section{ORGANIZACION JURIDICA POSITTVA DE LA INSTITUCION PROTECTORA DE MENORES E INCAPACES}

Dentro de la estructura de la Institución Protectora de menores e incapaces, la patria potestad constituyc la figura básica; y es a falta de clla que cntran a funcionar las figuras supletorias de la tutela y la curatela. Ello responde al sistema adoptado en nuestro derecho positivo por el cual se encarga a la familia eleuidado de la persona y los bienes de los menores y los incapaces; de tal forma quc, cn casi todos los casos, son parientes del menor o el incapaz quienes han de protegerles. Se comprucba la integración de todas esas figuras en una sola Instifucion Amparadora: todas procuran el mismo fin, se sustentan sus semcjantes fundamentos y se sirven de parecidos medios. Por tanto, son aplicables a la tutela las normas de la patria potestad y a la curatela las reglas de la tutela, que 
no aparezcan modificadas especificamente por disposiciones propias de cada figura.

Con relación a la patria potestad, las facultades que integran la autoridad paterna son de naturaleza compleja; ordinariamente asumena la vezla condición de derechos y deberes: "al atrihuirle estas potestades, la ley le reconoce un derecho natural, pero le impone al mismo tiempo su cumplimiento como una obligación. Se conjugan así el interés paterno con el familiar y social, dando origen a esta categoría de derechos-deberes quecaracterizan la institución ". En lo que respecta a la tutela, el tutor viene a llenar el vacío dejado por el padre. De ahi que sus atributos y sus deberes sean análogos pero no iguales; "porque la relación patemo-filial surge de la sangre, mientras que la que existe entre tutor y pupilo es una creación humana, un remedo imperfocto de la naturaleza"s. Por tanto, si bien se tiene presente la imagen de la patria potestad, los poderes de los tutores son menores y, correlativamente, mayor el control del Estado. Con referencia a la curatela, las atribuciones que se otorgan al curador tienen por objeto preservar la salud del incapaz y procurar su rehabilitación, así como también evitar que, por su incapacidad, sea perjudicado en su patrimonio. En tal virtud, al fijarse judicialmente los derechos-deberes del curador, se establece una estricta supervigilancia del Estado en el cjercicio de sus funciones.

En general, el régimen jurídico de la patria potestad, la tutela y la curatela determina a los padres, los tutores y los curadores el deber y el derecho de cuidar de la persona y bienes de los menores y los incapaces. En el aspecto personal, establece los derechos-deberes de asistencia y educación, de corrección y vigilancia, de tenencia y representación. En el ámbito patrimonial, scñala el derecho-deber de administración de los hienes de menores e incapaces y, únicamente en el caso de la relación paterno-filial, prescribe el usuinucto legal sobre tales bienes y en favor de los padres.

\section{EL DERECHO-DEBER DE ADMINISTRACION DE LOS BIENES DE MENORES E INCAPACES}

En la Institución Protectora, el derecho-deber de administración de los bienes de menores y de incapaces es una potestad personalísima y por tanto intransferible, sea a título gratuito y/u oneroso. Tiene por objeto no sólo la 
custodia y conservación de los bienes, sino también procurar un incremento normal del patrimonio por medios prudentes, que eviten en lo posible todo riesgo.

Precisamentc, para cvitar los mancjos inescrupulosos o arriesgados, el régimen jurídico de la patria potestad, la tuicla y la curatela reglamenta minuciosamente las facultades de los padres, los tutores y loseuradores, ya sea permiticndo la realización de cicrtos actos (por lo común, actos de mera conservación o de administración ordinaria), ya sea requiriendo la autorización del juez para la celebración de ciertos actos (por lo general, actos de administración extraordinaria o de disposición), ya sea prohibiendo de manera ahsoluta o relativa la verificación de ciertos actos (actos de enajenación y gravamen) ${ }^{3}$.

Por otra parte, mayores son las restricciones al derecho-deber de administración de los tutores y los curadores con respecto a los padres. Ello se refleja en las obligaciones de los primeros de realizar inventario judicial de los bienes del menor o el incapaz, de constituir garantía suficiente para asegurar la responsabilidad de su gestion, de discemir el cargo judicialmente y de rendir las cuentas de su administración periódica; las que no se presentan sino excepcionalmente en el caso de los padres.

De otro lado, el desempeño de los padres, los tutores y los curadores en la administración de los bienes de menores e incapaces debe ser diligente, cuidadosa y escrupulosa. Este es el criterio rector del modo de actuar en el manejo del patrimonio. De tal manera que, en el caso de los padres, se sanciona con la pérdida de la administración el poner en peligro los bienes de los hijos al ejercer la patria potestad; $y$, en el caso de los tutores y los curadores, se sanciona con el cese en el cargo (remoción) el causar perjuicio al menor y/o cl incapaz cn sus intereses.

En lo que respecta a los terceros con los cuales los padres, los tutores y los curadores hayan podido celebrar ciertos actos-durante la administración de los bienes de los menores y/o incapaces- sin observancia de las preseripciones del ordenamiento juridico-positivo, se sanciona la invalidez (uulidad) de los mismos; schalándose a los legitimados para accionar por la nulidad.

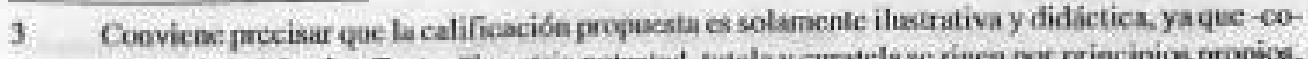

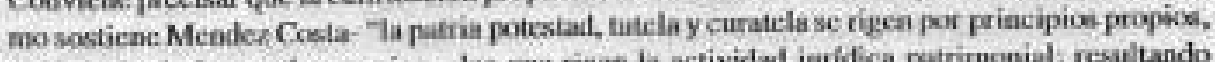
distintos $y$ de jenurguias soperior a los que rigea la actividal jeridica putrimenial, resaltando

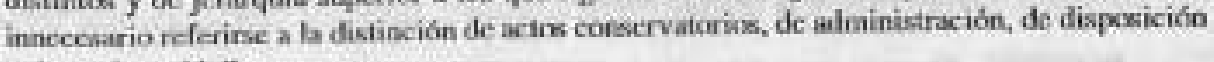
y de csiajeaación":"

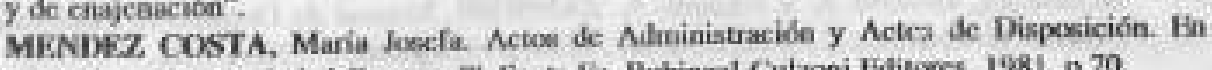

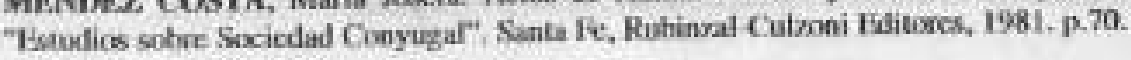




\section{LA FACULTAD DE ARRENDAR BIENES DE MENORES Y/O INCAPACES.}

En mayor o menor grado, el régimen juridico de la patria potestad, la tutela y la curatela circunscribe a la obtención de formas habilitativas' y al establecimiento de atribuciones legales facultativas y limitativas (prohibiciones), la potestad de arrendar bienes de menores e incapaces. Tales preseripciones son establecidas, independientemente si la determinación comprende bienes muebles o immuebles; y consisten en la obtención previa y necesaria de la autorización judicial para celebrar el respectivo contrato de arrendamiento, en el sefialamiento de plazos máximos a los que se sujetarán los mismos y en el establecimiento de los aleances de las potestades legales.

Por otro lado, siendo susceptible de terminar la patria potestad, la tutela y la curatela por cumplir el menor la mayoría de edad o cesar su incapacidad o por levantarse judicialmente la interdicción y declararse la rehabilitación del incapaz, es evidente y natural que al producirse tales acontecimicntosel contrato de arrendamiento concluya. Se declara, así, que los arrendamientos de bienes de menores y/o incapaces "Ileva implícita la condición de acabar cuando concluya la patria potestad, tutela o curatela, aun cuando cl arrendamiento sea por tiempo fijo"s.

Debe tenerse presente que si tales acontecimientos se produjeran antes del vencimiento del plazo del contrato de arrendamiento, la conclusión del mismo importa la reducción del plazo pactado, incluso con autorización judicial; no surtiendo efectos, por tanto, más allá de los mismos.

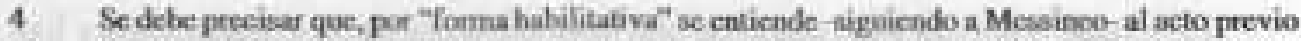
y accesario "que sirve para inicerar determinados actos jurfilicce y para conferit et poder de disponer a bi parte, removiendo limites a la eficacis de los mismos aun pudiendo-estos-ser, y siendo of crdinario, validoe en sf y por sh. I a falta de forma habilitativa los priva de eficacia". Tal es el caso de la autexizaci6o judicial exigible paún que determinadow actoo, que exceden de. la administración ontinaria, puodea ser practicados por los padres, tatores y euradores. Sirve paru remover límites al poder de dispowicion de ke scjeline que represcetan a menores e incapabes,

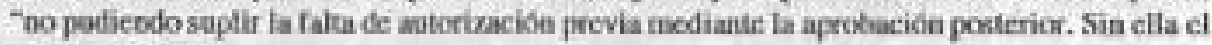
acio es incficar".

MESSINFO, Francenco. De alguoon actos necesarice para conferir clicacia a delemainadrs negocios. En, "Marual de Derecho Civil y Cumercial": Tamo II. Buenos Aires, Edicioecs Juríticas Huropa-Ambrica, 1979 , p. 4 ing

5 Bosszke, Gustavo A. y Eduudo A. ZANNONI. Manal de Derecho de Fumilia, 2ila.

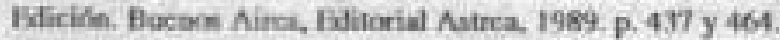




\section{LOS ANTAGONISMOS DEL REGIMEN JURIDICO DEL CODIGO CIVIL PERUANO.}

El régimen jurídico del Código Civil peruano, en to que se refieresa la facultad de arrendar bienes de menores $\mathrm{c}$ incapaces, es universal porque comprende tanto los bienes muebles como los bienes inmuebles; es complejo, con relación a las facultades de los padres, los tutores y los curadores, porque según el plazo del contrato de arrendamiento establece o no restricciones y prohibiciones. Con respecto a la sanción por la inobservancia de las prescripciones legales es mixto, por cuanto cstablece la nulidad del arrendamiento practicado por más de tres años, sin autorización judicial (forma habilitativa) y la reducción del término excesivo al plazo máximo legal de seis años para arrendar bienes de menores $\mathrm{e}$ incapaces; interpretándose jurisprudencialmente que cl arrendamiento celebrado sin autorización judicial produce efectos sólo dentro del plazo permitido para actuar sin restricciones, en aplicación del principio de conservación de acto jurídico (utile per inutile non vitiantur) relativo a la extensión de la nulidad (nulidad parcial). Por otra parte, la existencia de una norma específica en el articulado del contrato de arrendamicnto (artículo 1688 del Código Civil) y la distinción de un tratamiento particular en la legislación sobre alquileres de predios destinados a casa-habitación (artículo 7 del Decreto Ley 21938) que remite lo concernicnte al arrendamiento de bienes de menores e incapaces a lo previsto en el Derecho de Familia, evidencia el carácter especial y excepcional del régimen. De otro lado, si bien no se contempla como causal resolutoria del contrato de arrendamiento el término de la patria potestad, la tutela y la curatela por cumplir el menor la mayoria de edad o cesar su incapacidad o bien levantarse judicialmente la interdicción y declararsela rehabilitación del incapaz, consideramos que tal efecto es implicito y connatural al acto.

En lo que se refiere a la patria potestad, el inciso 1 del artículo $448 \mathrm{del}$ Código Civil establece que los padres necesitan autorizacion judicial para arrendar por más de tres años los bienes del menor. En concordancia, el artículo 1688 del Código Civil precisa que cuando el bien arrendado pertencece a incapaces -lo que incluye a los menores de edad-el plazo no puede ser mayor de seis anos; disponiendo que todo exceso se reducirá al plazo de ley. De ello se infiere que:

1.- Los padres están facultados para arrendar bienes del menor sin requerir autorización judicial, cuando lo efectúen por un plazo menor de tres aกิos.

2.- Los padres nceesitan autorización judicial (forma habilitativa) para 
arrendar los hienes del menor por un plazo mayor a tres años pero menor de seis aก̃os.

3.- Los padres están prohibidos de arrendar los bienes del menor por más de seis años (limitación a la facultad de arrendar).

Por otra parte, en el artícula 449 del Código Civil se indica que la autorización judicial será concedida conforme a los trámites establecidos en el Código de Procedimientos Civiles para enajenar u obligar bienes de menores; y que, en tal procedimiento, debe oírse -de ser posible- al menor que tuviere dieciséis años cumpliđos, antes de prestar su autorización. No se pronuncia sobre la imposibilidad de suplir la falta de autorización judicial previa y necesaria mediante la aprobación posterior.

De otro lado, se establece que la no obtención de la autorización judicial, cuando sea necesaria, provoca la invalidez del acto celebrado -pudiendo demandar la nulidad las personas legitimadas por el artículo $450 \mathrm{del}$ Codigo Civil- y que el exceso del plazo convencional con relación al término legal, importa una reducción al plazo máximo permitido por ley y no la invalidez del acto celebrado. Jurisprudencialmente ${ }^{6}$, se ha interpretado que el arrendamiento celebrado sin autorización judicial produce efecto sólo dentro del plazo permitidopara actuar sin restricciones, en aplicación del principio de conservación del acto jurídico (utile per inutile non vitiantur) relativoa la extensión de la nulidad? y de la regla por la cual el acto practicado por cl representante legal traspasando

Finel Dictamen IFesal de fecha 20 de Julio de 1953, rocaido enel Eupodiente N 322/53 - Procode de Arrequipat, se declara que: "si bica es verdad que es fundada la nulidad del contrato de locación. conduceión celcleado por escritura póblica" sin autorización judicial y "por habersec erecolido de los tres años permitives por la ley; no mesos cicrto es que dicha oulided no afoeta al dicrocho" del areendatario "pani oponerse a la entrega del immucble", ya que el coetrato celetrado "es yalido por fos primeros tres allos y la uulidad demandata snlo puede afectar el exeeso de dos añ̄s, por falta de antorización judicial", Se trata de un contrato de arrendamiento sobre el immucble de ana menor, celehrado por su vadre sin autorinación judicial y excediendose de los planos lepales. Ia Corte Supreana, en su igecutoria de fecha 10 de Agosto de 1953, de conformidad con el Dictamen Füscal aludido, deslaró no haher aulialad en la secniencia do vistu que revocando la apelasla dis pono la improcedencia de la demanda en cuasto a la devolución del inauehie materia del litigio, (Ea revista de Jarispnidencia Fenana $N^{*} 117$. Año 1953. p. 1371).

7 Ia doctrima nacional reconoce qoe pocke distinguirse estre bulidad total y nulidad parcial (conforme Iexha Burandiuría, Vidal Ramírc), Se parte de la premisa de la separahilidad del eonirnido del urin, de aes disposiciones o cláusulas, y utahie a la extensión de la aulídad del

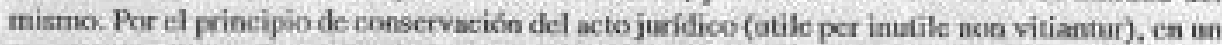
contrato un el que ans purte de sa contrnido es inefica, debe eontinuar siendo eficaz, en lo restante y llenar on lo posibie la fancí́n cecobinica persezuida por las partes: pemo para que ello fuheione, se roquiere que lal contenido sca susceptible de divisifn, sin que se destruya la escencia del conjantos, cono consecuencia de la convención o de la ley coando por moma imperativa asé se establiryra 
los límites establecidos por la ley o bien obrando sin las necesarias formas habilitativas es ineficaz respecto del representado (menor o incapaz) y sólo produce efectos dentro de los alcances permitidos legalmente ${ }^{n}$. En tal virtud, el contrato de arrendamiento celebrado por los padres excediéndose de los límites y violando sus facultades u obrando sin autorización judicial no produce efectos sino hasta el vencimiento del plazo permitido para actuar sin restricciones; to que importa una reducción del exceso al término máximo de ley ${ }^{9}$. Siendo asf, secomprucba que nuestro ordenamiento jurídico-positivo no se pronuncia sobre los límites para que el acto celebrado excediendo los alcances -o violando las facultades o sin autorización judicial- pueda ser ratificado por los menores al llegar a la mayoría de edad o cesar su capacidad y por los incapaces al levantarse

Asf, como se precis6, la institachba Protectera reconoce el derecbo-deber de representación de los menores c incapaces a cargo de sus padres, totares o curadores. Fs un caso de representación legal o nocessaria, que tienc por objeto hacer posible la participaciós de los menores e incapaces eo la vida jurídica; reposay está sapeofitada a la ley, la que irapone las facul taders de las que puode hacer uso el representante, asf curno sus obligaciones y responsabilidaules. Ia voluntad del representaate, de conformidad con las facultudes que le evafiere la ley, es la que da logar a la formación del acto jurílico, cuyos efeetios van a estar dirigidos al menor o incapaz represeatado. Sin embargo, puedesuceder que tales representantes traspesen queriendo osín querer, los límiles asignados por la ley (conforme Stolfi) o bien olsen sia las necesarias formas habilitativís (coaforme Messineo). Fstas circunstancias son casos de representación sin poder. Como consecucencia de ello, el acto juridico en el cque el represeatanie se ha exicedido de los límilus o ba violado sus facultades o se ha atribuido una representación que no tiene es ineficar, con relación al representado (cosforme Videl Ramirez). No produce efectos viaculantes respecto del así reprezentado y se encuentra sespesdido en calanto a su inefieacia con relación a estes, sỉn perjuicio de las responsabilidades qoe resulten frente al representado y a los teroeros. Bn tal sentido, el contrato de arrestauicato practicaulo por loo padres, los tutores o hos carradoress traspacando los límites establecidos por la ley o bien obrando sin las necesarias formas babilitativas es ineficaz respecto de los mencres eincapaces y sólo produce efectos dentro de los alcances permitidos legalmente.

9 Ruhio Correa, al analizar el artículo 450 del Cócigo Civil, precisa que "resulta ser una norma confusa que percece estar sonctido a la anulabilidad antes que a la sulidad. Ll asunto no es ocioso por dos ranones: si se trata ca cfecho de una nalidad, debea foncionar las reglas de legitimación del arlículo 220 al hado de las del 450 del Código Civil; sin ernhagen, esta óltima norma parnoce exclairlas. De stro lado, s i tratamos de nulidad, también bay que cresiderar que el plazo de dos años sería de caducidad y no de prescripción, dehido a que le roourta sustuntivamente cn su extension; aunque el citado plaso es más cercanoal de la anolabilidad previsto en ef articulo 2001 inciso 4 del Codjgo Civil, que al de la nelidsd establecido en el inciso 1 del mismo disponitivo. Fstamos aquí, por consigaicnte, ante una situación de interpretación, donde hay que determinar una upeico: o se trata de una nulidal por el texto expreso, o se trate de ena anuluhitidad por el sentido de la disposiciones; encontrándose, la solución definitiva al dilema, sólo jurisprudeacialmente". Coocluye ques, ante cl lexto expreso de la norma, se tratu de unur malífad y. por consiguicate, "que estamos uste un planode caducidad, y que el Ministerio Pdbitico pande seguir la nalidad, o disclasarle de oficie cl Jacz. Solo estaría restriagida la legitimación netiva de terceros eo contemplados en el artículo 490 , ys quesu bexioexpresunsente dice quiences pocalen accionser.

RUBso CORREA, Marcial. Nulidad y Anulabilidad: La Invalidez del Acto Jurífico, I.ima,

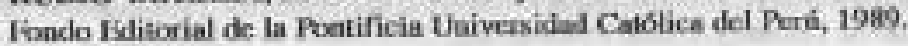


judicialmente la interdiceión y declararse su rehabilitación.

En lo concerniente a la tutela, el inciso 1 del artículo 532 nos remite al artículo 448 del Código Civil; en consocuencia, cl tutor nocesita autorización judicial para arrendar por más de tres años los bienes del pupilo. Sin embargo, el artículo 538 en su inciso 4 prescribe que los tutores están prohibidos de arrendar por más de tres años los bienes del pupilo. La evidente defieiencia Icgislativa se agrava cuando, en aplicación del artículo $1688 \mathrm{del}$ Código Civil, se establece que el plazo máximo legal para arrendar bienes de incapaces -loque incluye a los menores- es de seis afios ${ }^{10}$. En la práctica, tales contradicciones podrian ocasionar perjuicios a los menores por lo que ante semejantes eventualidades, consideramos que el juez debe aplicar los principios generales, según loscuales la patria potestad, la tutela y la curatela son instituciones establecidas para beneficio de los menores e incapaces y que, la integración de todas esas figuras en una sola Institución Protectora, evidencia la existencia de un único rćgimen legal de la facultad de arrendar bienes de menores e incapaces; siendo aplicables, por tanto, a la tutela -y tambien a la curatela- las reglas expuestas para la potestad paterna.

Con relación a la autorización judicial y a la intervención, si fuere posible, del menor que tenga dieciscis años cumplidas en el procedimiento para conceder aquélla, los artículos 533 y 534 nos cnvían a lo expuesto, cn el artículo 449 del Código Civil, para la patria potestad. De igual manera, se sanciona con la

En cl Código Civit de 1936, tales contraliceiones no se presentahan.

Asi, en el inciso 3 del articulo 522 se indicaha que el totne necesila autorizaciben jocficial pars. arrendar hirnes del menor por mist de tres ahos; estableciendo ta prohibicióen de arrendarlos por infs desecis afios, de acuendoconel inciso 4 del articulo $52 x$. Nor su parte, el articulo 1494, referido al contrato de loxeación-condección, remitia a las nomas de la tutela el arrendarniento sobre bienes de meoses e incapaces. De otrolado, por expresa ramisib́a de los artículios 413 y 558 , tales

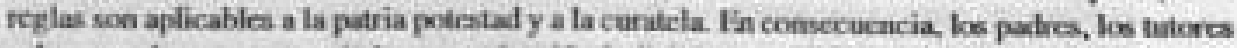
y Irs curadores no necositaban autorización judicial para arrendar los bicnes de menoes $e$ incapaces por menos de troi af́n; les cra coligatcrio rocabar haeterización judicial cuando el

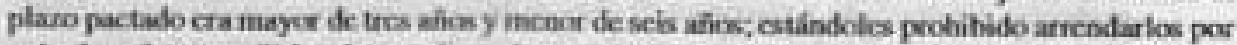
más de seis afios. Tules focron los critrrios del anteproyccto Cornejo Chávex. (1980) y del proyectodela Comisión Refornaikon (1981). Convienc precisar que, tantocl antrproyectocomo

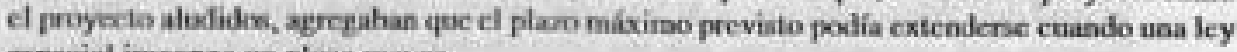
eapecial imponga ua plavo mayor.

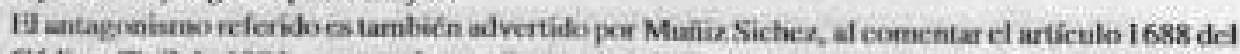
Codigo Civil de 1984; agregando gue "es vendad que a los incapaces a que se refiere el articulo

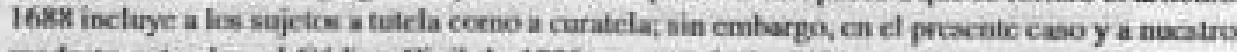
modesto entender, el Cledigo Civil de 1936 es su articulo 1494 era mís preciso, poresto que ostahlecta que respecto a los menures e incipaces regía el inciso 4 del articulo 528 , es decir, que lus tufores estahan probibidos por mis de scis aliks a amrndar los hienes def menor".

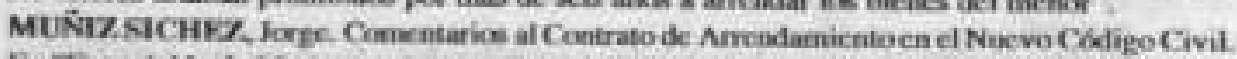
Fin Tajenición de Motivos y Corsentarios at Cóligo Civil". Torno VI. Compitacides efoutuada por Delia Kevercolo de Detakey. I inu, 1985. p. 365 , 
invalidez (anulabilidad) el acto celcbrado por el tutor sin autorización judicial; y, que el exceso en el plazo permitido por ley importa una reducción al máximo legal y no la invalidez del acto celebrado. En torno a cllos, nos remitimos a lo expuesto $\mathrm{cn}$ la parte correspondiente a la patria potestad.

De otro lado, siendo aplicables a la curatela las reglas de la tutela, es incuestionable que los contrasentidos de ésta se presentan en aquélla; refiriendo los comentarios a lo explicado anteriormente sobre la tutela. Empero, insistimos, por la integración de todas estas figuras en una sola Institución Protectora que provoca la aplicación a la tutela $-y$, en última instancia las de la potestad paterna-y no encontrandodisposiciones específicas y propias de cada figura que den un tratamiento particular al arrendamiento de bienes de menores e incapaces, se constata la cxistencia de un régimen único referido a tal facultad; siendo aplicables, por tanto, la reglas expuestas para la potestad paterna al cese de la tutela y la curatela.

Como se apuntó, si bien consideramos que el efectoresolutorio del término de la patria potestad, la tutela y la curatela por cumplir el menor la mayoria de edad o cesar su incapacidad o levantarse judicialmente la interdicción del incapaz frente al contrato de arrendamiento de bienes de menores e incapaces es implícito y connatural al acto mismo. Pareciéranos más conveniente prever Iegislativamente tal consecucncia a fin de despejar toda duda y otorgar mayor seguridad jurídica a los interesados. De tal forma que si tales acontecimientos se produjeran antes del vencimiento del plazo del contrato de arrendamiento, la conclusión del mismo importaría la reducción del plazo pactado, incluso con autorización judicial, por mandato de la ley"l.

Por otro lado, que cualquier otra eventualidad difcrente a las antes

En el Dictamen Fiscal de fecha 13 de Diciemine de 1887 , recaido en el Cuaderno $\mathrm{N}^{2} 642$. Procede de Lima, señala que "el padre que administra y usufructỉa los bienes del hijo, tiene por límite de sas derechos, en cuanto al tiempo, la incapacidad del menor, para dirigirse por sí mismo; asi es que, una ver que cl mersx licga a la mayorla y cesa la patria polestad, tienen que terminar les contratus de locación, hochos en su noxnbre". La Corte Suprema, en su Fijecutoria đe fecha 5 de Fecro de 1888, declar6 -de confonsidad con lo dicturninado por cl sentor Fiscalno haber bulidad en la sentencia de vista que rewocando la apeladia declara que el arreadamicato otorgado por la madre duranie la minoria de eilad de sus hijos, ha terminado respecto de ćstoot, por liegar a la maycría; teniendo su derecho cepectito pera acondar con cl tenedor de la finca la reata qoe les eonespooda.

Fste criterio jurisprudencial, además de moconocer el efecte connatusal de roseloción del contrato de arrendamicnto de hienes de mebores por llegar estos a la mayoria de edad y cesar. por tanio, la patria potestad, deterwiaa implicitameate una declatación de ineficacia respecto de los intensados en lo concerniente al plazo pactablo, el mismo qee se ve redocido. (En Asales Judiciales de La Corte Suprema de Justicia. I880-1884. Tomo IV. Lima, Ireprenda La Indastria, 1911, p, 502-505. 
mencionadas se extinga la patria potestad o que provoque la pérdida, privación, limitación o suspensión de la patria potestad paterna o que cause la conclusión de la tutela y la curatela o del cargo de tutor o curador, no puede influir en la relación contractual trabada con el tercero, por no alcanzarle las consecuencias de hechos a los que es ajeno.

Asimismo, estimamos conveniente para proteger los intereses de los menores y/o incapaces precisar, a nivel legislativo, la imposibilidad de suplir la falta deautorización judicial previa (forma habilitativa) mediante la aprobación postcrior.

Finalmente, crecmos que los menores al llegar a la mayoría de edad o cesar su incapacidad y que los incapaces al levantarse judicialmente su interdicción y declararse su rehabilitación, pueden ratificar el acto celebrado por su padre, tutor o curador, respectivamente, excediéndose de los límites o violando sus facultades legales o sin autorización judicial, sicmpre que el mismo no les haya producido perjuicios; procediendo conforme a las reglas del artículo 162 del Codigo civil $^{12}$.

\section{NECESIDAD DE DISIPAR LAS CONIRARIEDADES DE NUESTRO CODIGO CIVIL.}

Se ha comprobado que el régimen jurídico de la facultad de arrendar bienes de menores e incapaces muestra incongruencias, contrasentidos y vacios que pueden causar daños y perjuicios a los mismos. En tal virtud, urge armonizar la normatividad considerando que las figuras juridicas de la patria potestad, la tutela y la curatela se integran en una sola Institucion Protectora de menores e incapaces y que es consecuencia natural que al concluir aquéllas termine el contrato de arrendamiento. Una reforma en ese sentido debe tener presente que:

12. La pesibilidad de que los mencres llepados a la migoria de ealad paedan ratificar los actos crlebrados por sis podres sin autoricación judicial por los que se establectian obligaciones en interés de tales menores, ha sido admithla juraprudencialmente. Ia Corte Suprema, en su Fijecutoria de fecha 28 de Abril de 1930, ha deciarado que es validat la venta becha en favor de un menor, cuando posteriomente éste, ea el pleno goce y ejercicio de sus derechos, practica actos ratificalorios en relación a dicho eseatrato". Is di caso ise la adjudicacion de us inmocble en reanate póblico efectuado por la baadre ca nonabae de su mence hijo, sis auscrización jodicjal pura obligarlo. (En Anaiea Judiciales de la Corte Supremade Justicia. 1930. Tormo XXVI. Lima, I a Mascota, 1934, p. 77 85).

Aximismo, en su IFjecuteria de focha 7 de Julio de 1954, ha declerado que "si cuandoel menor

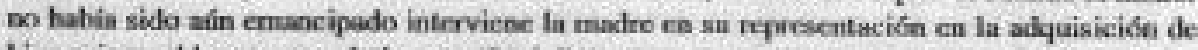

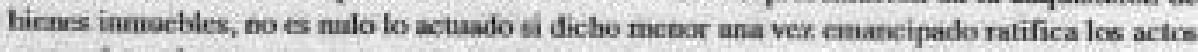
en que intervieo su reprosentante". (Th Revista de Jurisprudencia Peraasa 1954, p. 1504). 
1.- El regimen jurídico de la facultad de arrendar bienes de menores e incapaces es especial, de excepción universal, mixto, complejo y único. En consecuencia, los padres, tutores y curadores, respectivamente, están facultados para arrendar bienes del menor y del incapaz sin necesidad de autorización judicial, por un plazo menor de tres años; deben obtener previa y obligatoriamente la autorización judicial, cuando el plazo sea mayor de tres años pero menor de seis años; y, no pueden arrendarlos por más de scis años (prohibición).

2.-El contrato de arrendamiento practicado por los padres, los tutores y los curadores traspasando los límites establecidos por la ley o bien obrando sin las necesarias formas habilitativas (autorizacion judicial) es ineficaz respectode los menores y los incapaces - siendo, sin cmbargo, válido en sf́ mismo- y sólo producirá efectos dentro de los alcances permitidos legalmente, lo que importa una reducción del plazo convencional al máximo legal consentido. En todo caso, puede ser ratificado por el menor al llegar a la mayoría de edad o cesar su capacidad y, por el incapaz, al levantanse judicialmente su interdicción y declararse su rehabilitación, siempre que no les haya ocasionado perjuicios.

3.- Es imposible suplir la falta de autorización judicial previa y necesaria (forma habilitativa) para celebrar el contrato de arrendamiento por un plazo mayor de tres años pero menor de scis, mediante la aprobación posterior.

4.- La extinción de la patria potestad, la tutela y la curatela por cumplír el menor la mayorfa de cdad o cesar su incapacidad o levantarse judicialmente la interdicción del incapaz, provoca la resolución de pleno derecho del contrato de arrendarniento. Por lo que, de producirse tales eventualidades antes del vencimiento del plazo del contrato de arrendamiento, la conclusión del mismo importa la reduccíon del plazo pactado, incluso con autorización judicial.

\section{CONCLUSION}

El actual régimen juridico de la facultad de arrendar bienes de menores e incapaces patentiza disposiciones antagónicas e incongruentes que, en la práctica, podrían ocasionar perjuicios a los interesados. La necesaria revisión de la normatividad vigente tendrá por objeto conciliar y remitir a la organización jurídica-positiva de la Institución Protoctora de Menores e Incapaces lo concerniente a la facultad de los padres, los tutores y los curadores para arrendar bienes de aquéllos. Deesta manera, cualquier acontecimientoque involucre a los bienes arrendados de menores e incapaces será resuelto $\mathrm{c}$ interpretado de acuerdoa las reglas del Derecho de Familia; protegiendo, asi, los intereses de las partes implicadas. 


\section{A N EXOS}

A) En Revista de Jurisprudencia Peruana N"117-1953. p.137

Dictamen Fiscal.

Exp. 322/53-Procede de Arequipa.

\section{Señor:}

En el presente juicio seguido por doña M.M.V.A., curadora especial de la menor B.LL.G. con don F.P. sobre nulidad de contrato, por auto de fs. $144 \mathrm{vta}$. se ha concedido el recurso de nulidad interpuesto por la demandante contra la sentencia de vista de fs. 142 en cuanto revocándolo de Primera Instancia de fs. 85 via. declara improcedente el extremo de la demanda referente a la entrega del inmueble cuestionado.

Si bien es verdad que es fundada la nulidad del contrato de locacióncondueción celebrado por escritura pública, en cuanto al plazo de cinco años pactado en la cláusula sogunda, de conformidad con lo dispuesto por cl art. 413 c inciso 3 del art. 522 del C.C. por haberse excedido de los tres años permitidos por la Jey; no menos cierto es que dicha nulidad, no afecta el derecho del demandado don F.P. para oponerse a la cntrega del citado inmueble, pues apareciendo de autos que es inquilino del bien materia de la acción y que paga los arrendamienlos pactados, está amparado por la legislación vigente respecto al inquilinato y por lo tanto, es improcedente la entrega demandada. El demandado al celebrar el contrato de arrendamiento, actuó de buena fe y si se hubiera solicitado la autorización judicial correspondiente, se le hubicra concedido a la madre de la nombrada menor, ya que las condiciones del contrato eran beneficiosas para los intereses de la menor. El contrato de arrendamiento celebrado por el dernandado con la madre de la menor B.LL.G, de conformidad con lo dispuesto por el art. 1328 del C.C. es válido por los primeros 3 años y la nulidad demandada solo puede afectar el exceso de dos años, por falta de autorización judicial, lo que demuestra el justo título que ampara la condición de equilibrio que tiene el demandado don F.P. Además, la desocupación de los inmucbles urbanos no puede demandarse en la actualidad, por vencimicnto del plazo del contrato, sino en los casos especialmente contemplados por las leyes de inquilinato.

Por las condiciones expuestas y por los fundamentos de la sentencia de vista, opino que NO HAY NULIDAD en el fallo recurrido en la parte materia del recurso. 
García Amese.

Resolución Suprema

Lima, 10 de Agosto de 1953

Vistos de conformidad con el dictamen del señor Fiscal; declararon NO HABER NULIDAD en la sentencia de vista de foja ciento cuarentidós, su fecha cinco de Mayo último, en la parte materia del recurso, que revocando la apelada de fojas ochenticinco vuclta su fecha diecisiete de Junio de mil novecientos cincuentid6s, declaró improcedente la demanda interpuesta a $\mathrm{fs}$, dos por doña M.M.V.A. contra don F.P. y otros en cuanto a la devolución del inmueble materia del litigio y cxoneración del pago de costas; con lo demás que contiene condenaron en las costas del recurso a la parte que lo interpuso; y los devolvieron.

Sayán Alvarez.- Checa.- Maguiña.-Suero.-Valverde.- Serpa.-

Se publicó.- Dagoberto Ojeda del Arco.-Sccretario.

B) En, Anales Judiciales de la Corte Suprema de Justicia. Tomo IV- Años 1880-1887. p. 502.

\section{Dictamen Fiscal}

Excmo. Señor:

Donia M.G. viuda de A. dio en arrendamiento a unos asiáticos una finca situada en la calle del Capón de esta capital, en los términos y bajo las condiciones estipuladas en la escritura que en copia certificada obra a fojas 6 .

Esa finca había sido adquirido en remate público por don J.B.A., según consta de uno de los expedientes agregados, y habiendo fallecido intestado, se declaró por sus herederos a sus menores hijos legítimos don V., doña D., doña J., doña V. y doña R.A.

Al llegar a la mayoría, han promovido cuestión los hijos de A. sobre el arrendumiento hecho por la madre doña M.G., y sosticnen que hallegadoel caso de rescision por lesión, o sea por resultar muy baja la pensión conductiva, por haberse hechomal uso de la finca y por haher llegadocl caso previstocnel inciso $9^{\circ}$ del artículo 1606 del Codigo Civil.

Los asiáticos, despućs de haber perdido dos artículos sobre jurisdicción y personería, pretenden que el arrendamiento debe subsistir, porque el caso del artículo 1606 no es aplicable, desde que se refiere al arrendamiento hecho por el guardador y no al hecho por los padres, y porque hay escritura pública y es puntual el pago de las pensiones.

El juez resolvíí en la sentencia de fojas 73 , que el contrato dehía subsistir. porque no se había probado que fuera lesivo, ni que habían abusado los conductores, nique era aplicable el articulo 1606; peroel superior, considerando 
que el arrendamiento hecho por el usufructuario, no debe gravar al propietario, cuando estipula renta más baja, que la finca debe producir, desde que dicho sueño entra a ejencer sus derechos, $y$ que la caducidad declarada en el inciso $9^{\circ}$ del artículo 1606 Código Civil, es aplicable al arrendamiento hecho por los padres, ha revocado el fallo de primera instancia y declarado que ha terminado la locación respecto a los demandantes y que pueden acordar con el conductor de la finca la renta que corresponda.

El Fiscal por su parte es de sentir que el artículo 1606 Código Civil comprende en el inciso $9^{\circ}$ a los padres, por interpretación exiensiva de la ley, por cuanto la razón que se ha tenido para declarar la caducidad del contrato, es la misma. Tanto el guardador propiamente dicho como el padre que administra y usufructúa los bienes del hijo, tiene por límite de sus derechos, en cuanto al tiempo, la incapacidad del menor, para dirigirse por sí mismo; así es que una vez que el menor llega a la mayoría y cesa la patria potestad o la guarda, tienen que terminar los contratos de locación, hechos en su nombre; y el espíritu de los incisos $10^{\circ}$ y $11^{\circ}$ del dicho artículo 1606 , confirma esa doctrina, porque establece que el derecho de administración temporal solo puede comprometer en arrendamiento temporal también los bienes que se administran, a no ser que exprese su consentimientoel dueño que sea capaz de prestarlo, como sucede con los bienes de la mujer casada o con los de la testamentaria respecto de los herederos.

V.E. podrá pues, declarar que no hay nulidad en el fallo de vista, salvo más acertado parecer.

Lima, 13 de Diciembre de 1887.

Gálver.

\section{Resolución Suprema}

Lima, 5 de Enero de 1888.

Vistos; de conformidad con lo dictaminado por el señor Fiscal; declararon no haber nulidad en la sentencia de vista de fojas 84 veelta, su fecha 11 de Noviembre próximo pasado, que revoca la de primera instancia de fojas $73, y$ declara que el arrendamiento otorgado por doña M.G. de A. ha terminado respecto a las demandantes doña D., donta M.J: y donha V.A., quienes tienen su derecho expedito para acordar con el tenedor de la finca la renta que les corresponde; condenaron en la costas del recurso a la parte que lo interpuso; y los devolvieron.

Sánchez-Muñoz-Chacallana.-Alvarcz-Mariálegui,-Guzmán.-Galindo. Se public6 conforme a ley, de que certifico.

Juan E. Lama.

Procede de Lima. Cuaderno Nóm. 642. 